\title{
Is Ugly the New Beautiful? An Investigation of Perceptions of Beauty by Young Female Viewers of Ugly Betty in the US \\ Erin L Ryan*
}

Department of communication, Kennesaw State University, USA

\begin{abstract}
In today's society, media stereotypes of women have resulted in a perception of beauty that is often unattainable. Such media stereotypes often lend themselves to negative social comparisons. In this study, one hundred twentyeight middle school girls were surveyed to determine the relationship between viewing an "ugly" lead character on television and their perceptions of beauty. Results indicate that as the number of hours spent with television increased, traditional views of beauty increased and positive thoughts about one's own body decreased. Nonviewers of Ugly Betty had a higher regard for the character of Betty, and were more likely to compare their own bodies to those of their peers. These results are discussed in the context of social comparison theory and previous media effects research on stereotypes.
\end{abstract}

\section{Introduction}

Stereotypes are not inherently good or bad. however, the word "stereotype" does not typically evoke positive attributes. Rather, the common connotation of the term is largely negative, and thus people generally do not like to be stereotyped. Whereas past literature focused on how different groups have been stereotyped in the media [1] and ruminated on possible reasons why i.e., limited information [2], or the need for easily-understood content [3], more recently, scholars have begun to examine counter-stereotypes and their positive impact. The investigation of one such counter-stereotyped media character is the impetus for this project: "Ugly" Betty Suarez. During its original run, the $\mathrm{ABC}$ network's prime-time one-hour comedy Ugly Betty encompassed several different stereotypes, but perhaps the most notorious was the ugly Latina girl in the aesthetically-centered world of New York City fashion. Such a "fish out of water" storyline lent itself neatly to the scholarly examination of counter-stereotypes and social comparison.

Ugly Betty premiered in 2006 on US television, but was based on the enormously popular Colombian telenovela Yo Soy Betty la Fea "I am Betty the Ugly". USA Today explained the concept as: "A homely Queens gal gets her dream job at a tony fashion magazine and tries to fit in" [4]. In fact, Betty is hired for her position at Mode magazine precisely because the magazine's owner is confident that his playboy son, and editor of Mode, would never be attracted to her. Producer Salma Hayek explained that the premise of the show is really about "how Betty is not ugly, but she is working in an ugly environment full of beautiful people" [4]. Such an image-conscious program is perfect fodder for research on body-image stereotypes. And this study is a unique and important addition to the literature on body-image stereotypes as it targeted adolescent middle school girls as survey respondents.

\section{Stereotypes}

Classic definition of stereotypes guides this project: beliefs that assume all members of a group share "the same set of characteristics, attitudes, or life conditions". Such beliefs can be applied to individuals or groups based on age, race, ethnicity, gender, class, sexual orientation, religion, mental or physical disability, or physical appearance, among other factors [5]. In most cases, stereotypes are negative and limiting. It is important to highlight that such stereotypes are not idiosyncratic; rather, they are socially constructed and shared. And whereas people may not accept them as universal truths, most people easily recognize certain stereotypes. Some stereotypes may cut across cultures; for example, self-presentation behaviors such as shyness and dominance are fairly consistently gender-stereotyped in most cultures [6].

\section{Stereotypes and the media}

The mass media function as a vehicle for transmitting and reinforcing stereotypes. Whereas people certainly learn things from their immediate physical environment, media exposure also plays a powerful role, and stereotypes are often acquired indirectly from such exposure. Given the limited experience people have with unfamiliar groups, the media are powerful in developing, reinforcing, and validating stereotypical beliefs and expectations concerning those groups [7]. According to La Ferle and Lee audiences tend to rely on media to help them understand things they have not closely experienced. They argued that, "to provide an efficient path to cultural understanding, mass media employ stereotypes as a convenient categorization tool. The stereotypical images found in media messages are easily accepted because they are usually simple and have little ambiguity". Stereotypes act as self-perpetuating expectations about groups and their members by directing attention to information that is consistent with such stereotypes. Information that is inconsistent, on the other hand, tends to be ignored, discounted, or interpreted so that it confirms the initial impression.

As a business strategy, television programs rely on stereotypes because they need to attract a large audience; they must present content easily understood by a wide range of people [3]. Time limitations do not allow for complex character development, thus producers typically favor a more straightforward means of character development and identification. Stereotypes represent a vehicle to create easilyunderstood and identified character types [3]. Even television news relies on such stereotypes, as producers illustrate news stories using representative examples [8].

*Corresponding author: Erin L. Ryan, Department of communication, Kennesaw State University, USA, E-mail: eryan3@kennesaw.edu

Received June 28, 2013; Accepted July 01, 2013; Published July 06, 2013

Citation: Ryan EL (2013) Is Ugly the New Beautiful? An Investigation of Perceptions of Beauty by Young Female Viewers of Ugly Betty in the US. J Mass Communicat Journalism 3: 155. doi:10.4172/2165-7912.1000155

Copyright: (C) 2013 Ryan EL. This is an open-access article distributed under the terms of the Creative Commons Attribution License, which permits unrestricted use, distribution, and reproduction in any medium, provided the original author and source are credited. 


\section{Media effects of stereotypes}

Whereas stereotypes are often negatively valenced, they are not necessarily inherently good or bad [3]. Indeed, stereotypes exist which are not negative by any means. For example, men are typically stereotyped as doing well in math and Asians are assumed to have superior quantitative skills. When people violate the "good" stereotype, however, they are more likely to be evaluated negatively. For example, women are stereotyped as being "nurturing" and "loving;" when they violate this assumption, they are generally rated more negatively than women who confirm that stereotype. Beyond simply labeling people in positive and negative ways, stereotypes can become harmful when they elicit negative behaviors, such as objectifying and depersonalizing people, as well as denying someone their individuality.

The frequency with which stereotypes occur in the mass media raises concerns, because often times they are the dominant (or the only) images in the media of certain groups; ample positive images may not be available to counter negative images [3]. Van Evra [9] concluded that negative stereotypes offer potentially adverse effects because they can become the basis for behavioral scripts. Stereotype-based media messages can teach people how to respond to certain situations, thus perpetuating stereotypes about various social groups. Wicks explained, "Stereotyping may have a detrimental effect on attitudes and beliefs among audience members...the media are capable of shaping or reinforcing unhealthy attitudes, opinions, and beliefs by repeating stereotypical scripts" Clearly this is cause for concern among media scholars.

Macrae, Milne, and Bodenhausen (1994) explained that people fall back on their stereotypic preconceptions whenever they lack the ability or motivation to think more deeply about members of stereotyped groups. Inaccurate mediated images of groups may alter the social definition of those groups in other words; the way a group is portrayed in the media begins to represent societal beliefs about what members of those groups are "really" like. This ultimately negatively affects disadvantaged groups that have less control over the production of media myths, and struggle to project a positive image of their group [10].

\section{Stereotypes of body image}

Growing up, children are taught to value what society values, learning to see themselves as they are seen by others in terms of social standards [11]. As children develop, they become more sensitive to peer pressure and media messages, and may become particularly susceptible to popular media stereotypes, especially "those values and ideas presented by entertainment and fashion industries as vital elements of 'youth culture"' [12] Women in particular learn that their bodies and appearance are important factors; what a woman observes in a mirror is a measure of her worth $[13,14]$. Although people can hide certain things about themselves such as their tastes and personality, physical appearance is always visible. Weight becomes an important aspect of appearance and can affect a young woman's sense of social and psychological well-being [14-17].

Much research focusing on the attractiveness of women highlights body image, specifically thinness and obesity, and the various stereotypes associated with each of those traits. For example, the US culture views thin as beautiful, which is associated with good, positive attributes; alternately, fat is considered to be ugly, and ugliness is bad [11]. Thin, attractive people are viewed by others as being happier, more successful, smarter, more interesting, warmer, more poised, and more sociable $[18,19]$ while stereotypes generally depict large women as ungainly, unfeminine, and unworthy of appreciation [20].

In today's US culture, women are expected to be beautiful, and part of being beautiful is being thin. From media, messages and images emerge enforcing positive stereotypes of beauty and success [21,22]. These images then create the idea of what a "socially ideal" body looks like, and the positive attributes associated with that body. Historically, thin has not always been "in." For example, in the 1950s, Marilyn Monroe was a cultural icon of beauty, curves and all. However, since the 1960s, the ideal body type has become markedly slimmer and less curvaceous. Studies of Playboy centerfolds and Miss America contestants have found the women becoming markedly more slender since $1958[23,24]$. By the 1980s, [23] found that visitors to Madame Tussaud's London wax museum rated Twiggy as the most beautiful woman in the world. As the ideal body has slimmed down over the past few decades, it has moved further and further away from the average North American woman's physical reality [25]. This new ideal is placed before women as the mold into which their bodies should be constructed; however the reality is that the vast majority of women's bodies will never fit this mold.

Certainly, the mass media have been implicated time and again in the formation of unrealistically thin body ideals $[24,26,27,22]$ The female body is reflected and portrayed in media as an object of desire, shown in pieces; generally, the focus on females is either on their face, or on parts of their bodies, rather than the female as a whole [28]. The perfect body has flawless skin, a thin waist, long legs, well developed breasts [29] and the attributes of "beauty" and "morality" has become equated with thinness. To be a good girl, one must remain thin. This pressure to remain thin is intensified by a prejudice against being fat [29] and stereotypical "fat" qualities.

But why is being "fat" such a social stigma? Being fat can negatively stereotype people even at a very young age. For example, a classic 1961 study which asked a group of youngsters to pick whom they liked best from a set of pictures of several children found that, despite the inclusion of pictures of physically handicapped children in the line-up, the obese child was the last to be selected [30]. Cramer and Steinwert [31] found further support for such body size stigmatism in preschoolers of both genders. This "anti-fat bias" appears to emerge in early childhood and is sustained throughout adolescence and adulthood. One study found that even teachers, nurses, and parents rated overweight people as lazy, unmotivated, indulgent, unintelligent, and lacking in personal worth [32]. And media representations can reinforce such beliefs.

\section{Theoretical framework}

Social Comparison Theory provides an appropriate theoretical framework for this study of televised stereotypes and their effect on the audience, particularly within the context of young women's perceptions of weight-related stereotypes. Whereas the theory was not originally conceived as a media theory per se, many scholars have extended the ideas inherent in the theory to media contexts [33-38].

Social comparison theory proposes the idea that people compare themselves and their significant others to people and images they believe represent realistic attainable goals, and suggests that people make these comparisons automatically and unconsciously [39] Festinger's original theory included several hypotheses: that humans evaluate themselves by comparing their opinions and abilities to others; that there is a drive to achieve greater abilities; that a shift in the importance of a comparison groups will increase pressure towards uniformity within that group; and the distance from the mode of the comparison group will affect the tendencies of those making the comparisons [39]. The tenets of the theory center around the idea that people select an ideal 
image, then try to close the gap between this ideal image and their current perception of the self. When applied to mediated images that drive social comparisons, these ideas help create the framework for this study.

The negative impact of media depictions of thinness is dependent upon the occurrence and strength of social comparison [40]. Social comparison theory predicts that viewers are vulnerable to "forced" comparisons with media images; people are predisposed to make comparisons even at times when they are unaware of the comparisons they make, and [41] suggested that media images of the "thin ideal" may force such automatic comparisons. Thus, social comparison accounts for both intentional and unintentional processing of content. Even though people may not choose to compare themselves with the mediated "ideal," they may still automatically and unwittingly compare themselves to media images. Of course, they will be affected (usually negatively) by these comparisons, though to a lesser extent than those who do so intentionally [42].

Social comparison theory thus provides a crucial link between viewing, attitudes, and behavior [42]. Viewers who see inconsistencies when comparing themselves to other people are more motivated to "close the gap" on that comparison [41,43-45]. Adolescents turn to the media to find images of those they want to emulate and are motivated to act on the discrepancies they perceive as a result of those comparisons [42] Social comparison is thus considered a central contributor to body image [46]. Research has correlated social comparison and negative body image to mediated images, as the targets of appearance comparisons are often models and celebrities presented in the media [47]. Particularly for women, such comparisons help confirm the belief in the need to look like mediated images (i.e., thin, blond, and bigbreasted) and the need to act on that belief, particularly when highly motivated to achieve that goal [45].

\section{Adolescents and social comparison}

Adolescents tend to hold a "grass is always greener" attitude when comparing themselves to mediated images. With regard to advertising, [48] noted, "We are all potential victims of the invidious comparisons of reality to the world seen in advertising. Once convinced the grass is greener elsewhere, one's own life pales in comparison and seems a life half-lived". During adolescence, this sense of inadequacy is even more pronounced. Even 30 years ago, researchers like Freedman [49] noted:

The adolescent girl is also a consumer. Giant business and media networks join in trying to define, create and cater to her "needs" for beauty products... She is encouraged to put her best face forward but at the same time to hide behind an artificial mask. Ads which are designed to convince a girl that she must make-up and make-over to look acceptable eventually undermine her self-confidence and contribute to negative body image. (p. 33)

Of course, mediated models aimed directly at the child and adolescent market have become even more ubiquitous over the past three decades. And, knowing that children as young as seven use social comparison for self-evaluation, and that this tendency is even more pronounced for adolescents with low self-esteem and lower selfperceptions of physical attractiveness (Martin \& Kennedy, 1993), this appears to be a recipe for disaster. Indeed, Martin and Kennedy (1993) found that between 4 th grade and 12th grade, female's self-perceptions of physical attractiveness decreased significantly. During this crucial developmental stage, social comparisons to unrealistic mediated images can be extremely detrimental to perception of the self.

\section{Hypotheses}

Using social comparison theory as a guide, the purpose of this study was to discover whether viewing the television show Ugly Betty had any correlation with young female viewers' perceptions of beauty. Whereas past research has focused on the influence of media portrayals of thin and beautiful women on adolescent females, this study took a different approach, examining a lead female character with an atypical appearance (i.e., countersterotypical). Given that past studies have concluded young girls' self-concepts are negatively affected by exposure to the thin ideal, the following hypotheses were proposed.

With regard to television viewing overall:

H1: The more hours a girl watches TV, the more likely she will have traditional views on beauty.

$\mathrm{H} 2$ : The more hours a girl watches TV, the less positive thoughts she will have about her body during the day.

And specific to the program Ugly Betty:

H3: Girls who watch Ugly Betty will have higher regard for Betty than those who do not watch.

H4: Girls who watch Ugly Betty will be less likely to compare their bodies to the bodies of people they know than those who do not watch.

H5: Girls who watch Ugly Betty will be more tolerant of others' appearances than those who do not watch.

\section{Methods}

\section{Participants}

A paper-and-pencil questionnaire was distributed to 160 middle school girls in grades six through eight in a mid-size Southeastern US town. Approximately $80 \%$ of the questionnaires were returned $(\mathrm{N}=128)$. Ages of participants ranged from 11-15 years old. With regard to race/ ethnicity, $84 \%$ self-identified as White, $10 \%$ as African-American, $3 \%$ as Asian, and $4 \%$ as Native American Indian. Parental consent and student assent were obtained.

\section{Measures}

The survey was adapted using a body- esteem scale for adolescents and adults [50] a physical appearance comparison scale [51], a body comparison scale, and an expanded body-image ideals questionnaire [52]. Surveys were provided and conducted in a classroom setting. Participants were asked to check the response most comparable to their thoughts on the various questions regarding body image and social comparisons. Participants were asked to rate how closely they agreed with statements such as "I compare my looks to those of famous people," "I compare my body to the bodies of people I personally know," "I think it's better to be really thin," and "I think positive thoughts about my body during the day." Responses were given using a 5-point Likert scale, with 1 being "Strongly Disagree" and 5 "Strongly Agree".

The independent variables included whether they watched the television show Ugly Betty as well as the number of hours they watched television per day. Dependent variables included regard for the character Betty, comparison of respondents' body to the bodies of people they know, tolerance of other people's appearances, and sensitivity to friends' criticism of their appearance.

The dependent variables of "regard for the character Betty" and "tolerance of other people's appearances" were indices combining 
individual Likert-scale questions. The "regard" index combined respondents' views on Betty as attractive $(\mathrm{M}=3.45$, S.D. $=0.85)$, nice $(\mathrm{M}=2.08$, S.D. $=0.82)$, pleasingly dressed $(\mathrm{M}=3.71$, S.D. $=0.88)$, a potential friend $(\mathrm{M}=2.58$, S.D. $=1.05)$, and a potential popular classmate $(\mathrm{M}=3.76, \mathrm{~S} . \mathrm{D} .=0.71)$. Cronbach's Alpha was used to determine reliability of the decision-making index. The resulting statistic was 0.630 . The "tolerance" index combined respondents' views on whether they would talk to someone who was poorly dressed $(M=1.70$, S.D. $=0.87)$ or fat $(\mathrm{M}=1.69$, S.D. $=1.04)$. The Cronbach's Alpha result was 0.705. And the traditional beauty index was based on respondents' views on the importance of appearance $(M=2.33$, S.D. $=1.10)$, girls being well-dressed $(\mathrm{M}=2.66$, S.D. $=0.92)$, being attractive $(\mathrm{M}=3.45, \mathrm{~S} . \mathrm{D} .=0.85)$, and being thin $(\mathrm{M}=3.52$, S.D. $=1.03)$ and their views on whether Betty should lose weight $(M=3.66, S . D .=0.93)$ or change her appearance $(M=3.46$, S.D.=1.07). The Cronbach's Alpha result was 0.728 .

\section{Results}

\section{Descriptive statistics}

The independent variables examined included whether respondents watched the television show Ugly Betty and the number of hours of television watched per day. Of the 128 respondents, 103 affirmed that they watched the television show Ugly Betty, which approximates $82 \%$ of the sample. Respondents also reported watching an average of 3.5 hours of television per day.

\section{Hypothesis testing}

H1 was tested with a simple linear regression using the hours of television watched as the predictor variable and traditional views on beauty as the outcome. The regression was significant $(\mathrm{F}(1,126)=4.678)$, $\mathrm{p}<.05)$, with an R2 of .036. The Beta coefficient (.189) indicated a positive correlation. The number of hours of television watched per day was a significant predictor of traditional views of beauty.

$\mathrm{H} 2$ was also tested with a simple linear regression using the number of hours of television watched as the predictor variable and positive thoughts about one's body as the outcome variable. The regression was significant $(\mathrm{F}(1,126)=4.816), \mathrm{p}<.05)$, with an $\mathrm{R} 2$ of .037 . The Beta coefficient (-.192) indicated a negative correlation. As the number of hours of television watched increased, positive thoughts about one's body decreased.

$\mathrm{H} 3$ was tested with an independent-samples t test comparing the overall regard girls who watch Ugly Betty have for the main character versus those who do not watch. There was a significant difference between the two groups $(\mathrm{t}(126)=-2.485, \mathrm{p}<.05)$. However, contrary to the hypothesis, the average score from those who did not watch the show $(M=3.19$, S.D.=.53) was significantly higher than those who did watch $(\mathrm{M}=2.93$, S.D. $=.56)$.

$\mathrm{H} 4$ was tested with an independent-samples t test comparing the average score of how likely girls who watch Ugly Betty are to compare their bodies to people they know versus those who do not watch the show. A significant difference was found between the two groups $(t(126)=-3.056, p<.05)$. The average score for those who did not watch the show $(M=3.10$, S.D.=1.07) was significantly higher than those who did watch $(\mathrm{M}=2.45$, S.D. $=1.18)$.

H5 was tested with a Mann-Whitney U test comparing the level of tolerance of girls who watch Ugly Betty to those who do not. No significant difference was uncovered between the two groups ( $\mathrm{U}=1502.50, \mathrm{p}>.05)$. Thus, H5 was not supported.

\section{Discussion}

The world of broadcast television is driven by dollars, designed to appeal to the widest possible audience at the least possible cost. Television executives tend to stick with what has worked in the past, and consequently, stereotypes are often used in order to simplify the viewing process for the audience. Thus, it is not surprising that stereotypes portrayed on all genres of shows have been remarkably stable, with little change in gender stereotypes through the years [53]

One hypothesis predicted that watching the show Ugly Betty would result in a higher level of regard for the character of Betty. Though the findings showed significance, it was opposite from what the researchers expected; those individuals showing more regard for Betty did not watch the show. Perhaps the nature of the show is one possible explanation for this result. Betty is often the butt of jokes and a target of ridicule by other characters. Additionally, the show's focus on the world of high fashion may lend itself to a more judgmental world-view, particularly as it pertains to appearances. Since Betty is not viewed as physically attractive, it falls in line with previous research that other characters would not accept her appearance. Thus, viewers of the show could potentially see Betty as someone that does not deserve a high level of regard from the other characters because of her appearance, while non-viewers would not be influenced by the treatment Betty receives on the show.

Additionally, respondents who watched Ugly Betty were less tolerant of others' appearances than non-watchers of the show. In light of previous research, this result was surprising, yet may be explained using the aforementioned rationale of the ridicule the character faces on the show due to her appearance. However, surprisingly, the data also indicated respondents who watched the show were less likely to compare their own bodies to others. This would indicate that whereas these young viewers are critical of others, they are not turning that same critical eye to their own physical appearance.

This finding is intriguing and worthy of further study, especially as it relates to the argument in the literature linking exposure to media messages to low self-esteem and self-concept. Was there something about the content of this particular show that caused viewers to be less critical of their own appearance, but yet still criticize others' appearances? Future research can bear this out, perhaps via content or textual analysis of the program itself. There may be something about the particular type of counter-stereotypical messages in the program that somehow inoculates adolescent girls against self-criticism but still communicates that it is acceptable to judge others. Perhaps setting the show at a fashion magazine was enough to perpetuate this critical behavior toward others. And maybe, at the same time, viewers still absorbed Betty's message of "love yourself no matter what others say," which led to this seeming contradiction.

Time spent with television was also examined with respect to traditional views on beauty and thoughts about one's own body. Not surprisingly, as the hours of television increased, the likelihood that viewers would hold traditional views on beauty also increased; additionally, as time spend with television increased, positive thoughts about one's body decreased. These findings are similar to previous research conclusions, such as those finding that television promotes a slim waist to young female viewers [42], and that heavy television viewing typically leads to poor body image, particularly among girls [54-56].

No study is without flaws, and the present study is no exception. 
Citation: Ryan EL (2013) Is Ugly the New Beautiful? An Investigation of Perceptions of Beauty by Young Female Viewers of Ugly Betty in the US. J Mass Communicat Journalism 3: 155. doi:10.4172/2165-7912.1000155

The most notable limitations come from the sample itself. The sample of young girls was taken from an area of the Southeastern United States that struggles with obesity; a more full figured body image may be more the norm to young girls in this part of the country. The sample was also largely white, and the majority of the respondents were United States citizens; this may be the largest limitation of this study. The character of Betty is of Latina origin; though the characters in the show ridicule Betty for her appearance and not her cultural background, it must be recognized that there are different cultural standards when it comes to beauty. Perhaps results would have been different with a more heterogeneous sample. There is a definite anti-fat bias present when White women are surveyed but studies have shown that this "thin is in" perception may not hold true for women of color [57]. Future studies in this area should make every attempt to include viewers from diverse cultural backgrounds.

Indeed, future studies may also want to include males in the sample. Whereas much of the literature on body-image stereotyping and self-concept/esteem focuses on women, men are not immune to this phenomenon. Men's views of themselves and their expectations of women's appearances in relation to media consumption should not be left out of the equation.

\section{Conclusions}

The results of this study suggest the television show Ugly Betty is a double-edged sword with regard to young women viewers and feelings about beauty and appearance. Interestingly, those who do not watch the show seem to be more accepting of an "ugly" character, and all of the stereotypical attributes that come along with that. Viewers who do watch the show are less likely to engage in a comparison of their bodies to their peers, but are more sensitive to criticism about their own appearance. This could suggest that Betty may be good for attitudes about body image, but has a negative influence on appearance norms. Watching more daytime television does seem to correlate with traditional views on beauty, and watching more television overall seems to have a negative relationship with a positive mindset about one's body. These findings have implications for the understanding of the relationship between television viewing and views on women's appearance, and more specifically, traditional views on beauty. Further studies could examine other "nonconformist" lead characters with a focus on perceptions of beauty among girls to determine if Ugly Betty is an indication of a trend of if she's the only one breaking the stereotypical mold.

\section{References}

1. Smeesters D, Mandel N (2006) Positive and negative media image effects on the self. Journal of Consumer Research 32: $576-582$.

2. Rich E (1979) User modeling via stereotypes. Cognitive Science 3: 329-354.

3. Perse E (2001) Media effects and society. Mahwah NJ: Erlbaum.

4. Levin G (2006) Plot: Pretty is as pretty does. USA Today online.

5. Liebert RM, Sprafkin J (1988) The early window: Effects of television on children and youth. New York Pergamon.

6. Browne BA (1998) Gender stereotypes in advertising on children's television in the 1990s: A cross-national analysis. Journal of Advertising 27: 83-96.

7. Appiah O (2008) Stereotyping and the media. In W. Donsbach Ed, The International Encyclopedia of Communication. Waltham, MA: Blackwell.

8. Linn T (1996) Media methods that lead to stereotypes. In PM. Lester Ed Images that Injure: Pictural stereotypes in the media. Westport CT: Praeger.

9. Van EJ (1998) Television and child development. Mahwah, NJ: Erlbaum.
10. Collins ME (1991) Body figure perceptions and preferences among preadolescent children. International Journal of Eating Disorders 10: 199-208.

11. Hesse BS (1997) Am I thin enough yet? The cult of thinness and the commercialization of identity. Oxford University Press, New York, USA.

12. Attie I, Brooks GJ (1987) Weight concerns as chronic stressors in women.

13. Douglas M (1973) Natural symbols: Explorations in cosmology. Barrie \& Jenkins, UK.

14. Grabe S, Ward LM, Hyde JS (2008) The role of the media in body image concerns among women: A meta-analysis of experimental and co relational studies. Psychological Bulletin 134: 460-476.

15. Adams GR (1977) Physical attractiveness research. Human Development 20: 217-239.

16. Millman, M. (1980). Such a pretty face. Berkely Books, USA.

17. Rodin J, Sliverstein L, Striegel MR (1985) Women and weight: A normative discontent. In: T. B. Sonderegger (1985) Psychology and gender: Nebraska symposium on motivation . Lincoln: University of Nebraska Press.

18. Dion KK, Berscheid E, Walster E (1972) What is beautiful is good. Journal of Personality and Social Psychology 24: 285-290.

19. Cash TF (1990) The psychology of physical appearances: Aesthetics, attributes and images. In Cash TF \& Pruzinksy T, Body images development, deviance and change. Guilford Press, USA.

20. Braziel JE, Le Besco K (2001) Bodies out of bounds: Fatness and transgression. University of California Press, USA

21. Downs AC, Harrison SK (1985) Embarrassing age spots or just plain ugly? Physical attractiveness stereotyping as an instrument of sexism on American television commercials. Sex Roles 13: 9-19.

22. Garner DM, Garfinkel PE (1980) Socio-cultural factors in the development of anorexia nervosa. Psychol Med 10: 647-656.

23. Garner DM, Garfinkel PE, Schwartz D, Thompson M (1980) Cultural expectations of thinness in women. Psychological Reports 47: 483-491.

24. Wiseman CV, Gray JJ, Mosimann JE, Ahrens AH (1992) Cultural expectations of thinness in women: An update. International Journal of Eating Disorders 11 85-89.

25. Gimlin DL (2002) Body work: Beauty and self-image in American culture. University of California Press, USA.

26. Silverstein B, Perdue L, Peterson B, Bogel B, Fantini DA (1986) Possible causes of the thin standard of bodily attractiveness for women. International Journal of Eating Disorders 5: 907-916.

27. Silverstein B, Perdue L, Peterson B, Kelly E (1986) The role of mass media in promoting a thin standard of bodily attractiveness for women. Sex Roles 14 519-532.

28. Archer D, Iritani B, Kimes D, Barrios M (1983) Face-ism: Five studies of sex differences in facial prominence. Journal of Personality and Social Psychology 45: 725-735.

29. Thompson JK, Heinberg LJ, Altabe M, Tantleff DS (1999) Exacting beauty: Theory, assessment, and treatment of body image disturbance. American Psychological Association, USA.

30. Richardson SA, Goodman N, Hastorf AH, Dornbusch SM (1961) Cultural uniformity in reaction to physical disabilities. American Sociological Review 26 : 241-247.

31. Cramer P, Steinwert T (1998) Thin is good, fat is bad: How early does it begin? Journal of Applied Developmental Psychology 19: 429-451.

32. Puhl R, Browness KD (2001) Bias, discrimination, and obesity. Obesity Research 9: 788-805.

33. Corcoran K, Crusius J, Mussweiler T (2011) Social comparison: Motives standards, and mechanisms. In: D. Chadee (2011) Theories in Socia Psychology, Wiley-Blackwell, Oxford, UK.

34. Groesz LM, Levine MP, Murnen SK (2002) The effect of experimental presentation of thin media images on body satisfaction: A meta-analytic review. International Journal of Eating Disorders 31: 1-16.

35. Hafner M (2004) How dissimilar others may still resemble the self: Assimilation 
Citation: Ryan EL (2013) Is Ugly the New Beautiful? An Investigation of Perceptions of Beauty by Young Female Viewers of Ugly Betty in the US. J Mass Communicat Journalism 3: 155. doi:10.4172/2165-7912.1000155

Page 6 of 6

and contrast after social comparison. Journal of Consumer Psychology 14: 187-196.

36. Kim JH, Lennon SJ (2007) Mass media and self-esteem, body image and eating disorder tendencies. Clothing \& Textiles Research Journal 25: 3-23.

37. Polivy J, Herman CP (2002) Causes of eating disorders. Annual Review of Psychology 53: 187-213.

38. Trampe D, Stapel DA, Siero FW (2007) On models and vases: Body dissatisfaction and proneness to social comparison effects. Journal of Personality and Social Psychology 92: 106-118.

39. Festinger $L$ (1954) A theory of social comparison processes. Human Relations 7: 117-140.

40. Wilcox K, Laird JD (2000) The impact of media images of super-slender women on women's self-esteem: Identification, social comparison, and self-perception. Journal of Research in Personality 34: 278-286.

41. Goethals GR (1986) Social comparison theory: Psychology from the lost and found. Personality and Social Psychology Bulletin. 12: 261-278.

42. Botta RA (1999) Television images and adolescent girls' body image disturbance. Journal of Communication. 49: 22-41.

43. Wood JV (1989) Theory and research concerning social comparisons of personal attributes. Psychological Bulletin. 106: 231-248.

44. Kruglanski AW, Mayseless O (1990) Classic and current social comparison research: Expanding the perspective. Psychological Bulletin. 108: 195-208.

45. Wood JV, Taylor KL (1991) Serving self-relevant goals through social comparison. In J.Suls \& TA.Wills (Eds), Social comparison: Contemporary theory and research. Hillsdale, $\mathrm{NJ}$ : Erlbaum.

46. Jones DC (2001) Social comparison and body image: Attractiveness comparison to models and peers among adolescent girls and boys. Sex Roles, 45: 645-665.
47. Taylor CB, Sharpe T, Shisslak C, Bryson S, Estes LS, et al (1998) Factors associated with weight concerns in adolescent girls. International Journal of Eating Disorders. 24: 31-42.

48. Pollay RW (1986) The distorted mirror: Reflections on the unintended consequences of advertising. Journal of Marketing. 50: 18-36.

49. Freedman RJ (1984) Reflections on beauty as it relates to health and adolescent females. Women and Health. 9: 29-45.

50. Mendelson BK, White DR, Balfour L (1995) The body-esteem scale for adolescents and adults. Unpublished manuscript, Concordia University, Montreal, Canada. 76: 90-106.

51. Thompson JK, Heinberg LJ, Tantleff, S. (1991). The physical appearance comparison scale. The Behavior Therapist, 14, 174.

52. Szymanski ML, Cash TF (1995) Body-image disturbances and self-discrepancy theory: Expansion of the body-image ideals questionnaire. Journal of Social and Clinical Psychology 14: 134-146.

53. Signorielli N, Bacue A (1999) Recognition and respect: A content analysis of prime-time television characters across three decades. Sex Roles: A Journal of Research 40: 527-544.

54. Thompson JK, Heinberg LJ (1999) The media's influence on body image disturbance and eating disorders: We've reviled them, now can we rehabilitate them? Journal of Social Issues. 55: 339-353.

55. Maltby J, Giles D, Barber L, McCutcheon LE (2005) Intense-personal celebrity worship and body image: Evidence of a link among female adolescents. British Journal of Health Psychology. 10: 17-32.

56. Henderson V (2007) Longitudinal associations between television viewing and body mass index among white and black girls. Journal of Adolescent Health. 4: 544-550.

57. Fujioka Y, Ryan EL, Agle M, Legaspi M, Toohey R (2009) The role of racia identity in responses to thin media ideals. Communication Research. 36: 451474. 